\begin{tabular}{|c|c|}
\hline Title & Sulfate adsorption and surface precipitation on a volcanic ash soil (allophanic andisol) \\
\hline Author(s) & Ishiguro, Munehide; Makino, Tomoyuki; Hattori, Y asunobu \\
\hline Citation & $\begin{array}{l}\text { Journal of Colloid and Interface Science, 300(2), 504-510 } \\
\text { https://doi.org/10.1016/.j.jcis.2006.04.032 }\end{array}$ \\
\hline Issue Date & $2006-08-15$ \\
\hline Doc URL & http:/hdl.handle.net/2115/70737 \\
\hline Rights & $\begin{array}{l}\text { Copyright @ } 2006 \text { Elsevier Inc. A II rights reserved., (ब 2006. This manuscript version is made available under the CC- } \\
\text { BY-NC-ND } 4.0 \text { license http://creativecommons.org/icenses/by-nc-nd/4.0/ }\end{array}$ \\
\hline Rights(URL) & http://creativecommons.org/icenses/by-nc-nd/4.0/ \\
\hline Type & article (author version) \\
\hline File Information & Sulfate A dsorption and Surface Precipitation on a V olcanic A sh Soil .pdf \\
\hline
\end{tabular}

Instructions for use 


\title{
Sulfate Adsorption and Surface Precipitation on a Volcanic
}

\section{Ash Soil (Allophanic Andisol)}

\author{
Munehide Ishiguro $^{\mathrm{a} *}$, Tomoyuki Makino $^{\mathrm{b}}$, Yasunobu Hattori ${ }^{\mathrm{a}}$ \\ ${ }^{a}$ Faculty of Environmental Science and Technology, Okayama University, Okayama, 700-8530 Japan, \\ ${ }^{b}$ National Institute for Agro-Environmental Sciences, Tsukuba, Ibaraki 305-8604, Japan \\ * Corresponding author.
}

Address: Faculty of Environmental Science and Technology, Okayama University, 3-1-1. Tsushimanaka, Okayama, 700-8530 Japan

TEL/FAX: +81-86-251-8875

E-mail address: ishi@cc.okayama-u.ac.jp 


\section{Abstract}

Sulfate strongly adsorbs on metal oxides and soils with variable charges. However, its surface precipitation has not been clearly evaluated and its adsorption mechanism has been in dispute. In the present study, an allophanic Andisol, a typical volcanic ash soil having both negative and positive variable charges, was used to identify the adsorption mechanism of sulfate. Sulfate adsorption isotherms were obtained by a batch method at $\mathrm{pH}$ values of $4,5,6$, and 7 in a wide range of concentrations in a $\mathrm{Na}-\mathrm{H}-\mathrm{SO}_{4}-\mathrm{OH}$ system. Theoretical isotherms were applied to the measured values for the evaluation. The surface precipitation was detected by the measured adsorption isotherms, and the BET isotherm confirmed the presence of multilayer adsorption. Stronger and weaker adsorption sites were suggested by using the Langmuir isotherm for the monolayer adsorption. The adsorption energies obtained from the Langmuir equation and recent spectroscopic analysis suggested that the stronger adsorption corresponded to an inner-sphere surface complex and that the weaker adsorption corresponded to outersphere surface complexation. The BET and Langmuir equations showed three types of adsorption mechanisms for the sulfate adsorption on the soil.

Keywords: Surface precipitation; Sulfate adsorption; The BET equation; The Langmuir equation, Allophanic soil; Variable charge; Adsorption isotherm; Multilayer adsorption 


\section{Introduction}

Sulfate strongly adsorbs on metal oxides and soils with variable charges. However, its surface precipitation has not been clearly evaluated and its adsorption mechanism has been in dispute. Precipitation is enhanced near the solid-solution interface under undersaturated conditions [1]. According to surface precipitation, a chemical equilibrium model for metal cation sorption on metal oxides similar in concept to the BET isotherm has been proposed [2]. The BET isotherm has been applied to phosphate adsorption on calcite [3], exchange resin [4], and highly weathered soils [5], although the surface precipitation in these cases has not been obvious. Sulfate adsorption maxima have not been observed at least up to 500 ppm and the Freundlich equation has been adopted for sulfateretentive soils [6]. However, surface precipitation has not been reported with regard to sulfate adsorption.

Allophanic Andisol, a typical volcanic ash soil with significantly variable charges, exhibits both negative and positive charges under natural conditions [7-8]. The soil disperses well at low pH due to its predominantly positive charge and at high $\mathrm{pH}$ due to its predominantly negative charge. The soil permeability decreases at lower and higher $\mathrm{pH}$ because of dispersion and swelling of the soil [9]. However, the soil maintains a flocculated condition even at lower $\mathrm{pH}$ when sulfate is adsorbed on the soil due to its strong adsorption [10-11]. Nitrate flows faster in a volcanic ash soil when it coexists with sulfate because sulfate is highly selective over nitrate [12]. Inner-sphere surface complex formation of sulfate on allophone and allophanic soils has been suggested [13-15]. On the other hand, easily exchangeable sulfate has also been observed in volcanic ash soils [13, 16].

It has remained a point of dispute whether sulfate adsorption complexes form an outer- or innersphere surface complex at a mineral/water interface. The volume increase by dilatometry after sulfate adsorption indicates that sulfate dehydrates at the water/amorphous iron hydroxide interface [17]. Recent spectroscopic results suggest that sulfate forms both outer-sphere and inner-sphere surface complexes on goethite, and that quantities of the latter increase with decreasing $\mathrm{pH}[18-20]$. On $\mathrm{Al}$ oxide, sulfate exists predominantly as outer-sphere surface complexes, but a small fraction is also 
present as an inner-sphere complex at $\mathrm{pH}<6$ [20]. Sulfate adsorption on goethite is evaluated using the Charge Distribution Multisite Complexation model and compared with the spectroscopic work [21].

Our results allowed us to clearly detect multilayer sulfate adsorption on the allophanic Andisol and to theoretically confirm the surface precipitation using the BET isotherm. The monolayer sulfate adsorption mechanisms of the allophanic Andisol were also evaluated by the Langmuir isotherm.

\section{Materials and methods}

\subsection{Soil}

Allophanic Andisol (Hapludand), a typical volcanic ash soil, at the field of the National Institute for Agro-Environmental Sciences in Tsukuba, Japan, was used in the adsorption experiment. The soil was obtained at a depth approximately $90 \mathrm{~cm}$ from the 4Bw1 horizon. The predominant clays were allophane and imogolite. The specific surface of the soil obtained from the $\mathrm{N}_{2}$ adsorption was $2.113 \times 10^{5} \mathrm{~m}^{2} / \mathrm{kg}$ (QUANTACHROME AUTOSORB-1). Other physical and chemical properties measured by the National Institute of Agricultural Sciences [22] are listed in Table 1.

\subsection{Sulfate adsorption experiment}

Sulfate adsorptions at $\mathrm{pH} 4,5,6$, and 7 and at different sulfate concentrations (from 0.0015 to 850 $\mathrm{mmol} / \mathrm{L}$ ) in the $\mathrm{Na}-\mathrm{H}-\mathrm{SO}_{4}-\mathrm{OH}$ system were determined using a batch method. The adsorption amount was calculated by subtracting the sulfate amount remaining in the solution in the soil suspension from the input sulfate amount. Sulfate was added as a $\mathrm{Na}_{2} \mathrm{SO}_{4}$ solution and/or a $\mathrm{H}_{2} \mathrm{SO}_{4}$ solution to soil equilibrated at the prescribed $\mathrm{pH}$. $\mathrm{A}_{2} \mathrm{HO}_{4}$ solution was applied when the $\mathrm{pH}$ of the soil solution increased after sulfate adsorption until the $\mathrm{pH}$ recovered to the initially prescribed $\mathrm{pH}$. The added $\mathrm{H}^{+}$ amount as a $\mathrm{H}_{2} \mathrm{SO}_{4}$ solution was also inspected. The detailed experimental procedure was as follows:

1. Approximately $0.5 \mathrm{~g}$ of the soil was placed in a centrifuge tube, followed by $30 \mathrm{~cm}^{3}$ of a $1 \mathrm{~mol} / \mathrm{L}$ $\mathrm{NaNO}_{3}$ solution. The soil solution $\mathrm{pH}$ in the tube was adjusted to $\mathrm{pH} 8$ with $1 \mathrm{~mol} / \mathrm{L} \mathrm{NaOH}$ in order to remove naturally adsorbing sulfate. The tube was shaken well and allowed to stand for more than 3 
hours. It was then centrifuged, and the supernatant was discarded. This procedure was repeated five times.

2. After finishing step $1,30 \mathrm{~cm}^{3}$ of a $\mathrm{HNO}_{3}$ solution at $\mathrm{pH} 4$ or $\mathrm{pH} 5$ was added to the tube to create a soil sample at $\mathrm{pH} 4$ or $\mathrm{pH}$ 5. To create a sample at $\mathrm{pH}$ 6, $30 \mathrm{~cm}^{3}$ of a $0.001 \mathrm{mmol} / \mathrm{L} \mathrm{NaNO}_{3}$ solution was added to the tube. To create a sample at $\mathrm{pH} 7,30 \mathrm{~cm}^{3}$ of a $0.0001 \mathrm{mmol} / \mathrm{L} \mathrm{NaNO}_{3}$ solution was added. The $\mathrm{pH}$ was then adjusted to the prescribed $\mathrm{pH}$ with a dilute $\mathrm{HNO}_{3}$ solution. The tubes were shaken well and allowed to stand for more than 3 hours. The tubes were then centrifuged, and the supernatant was discarded. This procedure was repeated more than six times until the solution $\mathrm{pH}$ reached the prescribed $\mathrm{pH}$.

3. Sulfate solutions at the prescribed $\mathrm{pH}$ at different concentrations were prepared with a $\mathrm{Na}_{2} \mathrm{SO}_{4}$ solution and a $\mathrm{H}_{2} \mathrm{SO}_{4}$ solution. After finishing step 2, $30 \mathrm{~cm}^{3}$ of the sulfate solution was added to the tube. The tube was shaken well and allowed to stand for more than 3 hours. If the solution $\mathrm{pH}$ was the same as the prescribed $\mathrm{pH}$, the sulfate concentration of the soil solution was measured. If the solution $\mathrm{pH}$ increased more than the prescribed $\mathrm{pH}, \mathrm{a} \mathrm{H}_{2} \mathrm{SO}_{4}$ solution was added to the tube and the $\mathrm{pH}$ was adjusted to the prescribed $\mathrm{pH}$. Then, the sulfate concentration of the soil solution was measured. The sulfate concentration was measured by ion chromatography (HITACHI LaChrom), and the weight of the soil was determined.

The Al concentration of the final supernatant at pH 4 was measured by ICP-AES (Maxim III; Applied Research Laboratories). The soil surface conditions were not expected to change significantly even at $\mathrm{pH} 4$ because the $\mathrm{Al}$ concentrations were less than $0.017 \mathrm{mmol} / \mathrm{L}$.

A small amount of nitrate remained in the soil-water system. However, the influence of nitrate on sulfate adsorption was thought to be negligible because sulfate is highly selective over nitrate [12] and the amount of nitrate residue was small.

\section{Theoretical basis}

\subsection{The BET isotherm}


The BET isotherm was applied to the multilayer adsorption of sulfate on the soil. When we assume that the binding energy between sulfate and the soil surface, $\varepsilon_{S}$, corresponds to the monolayer adsorption energy $(\mathrm{J} / \mathrm{mol})$, and that the binding energy between sodium sulfate, $\varepsilon_{\mathrm{L}}$, corresponds to the energy for surface precipitation of sodium sulfate from the second layer to multilayer ( $\mathrm{J} / \mathrm{mol})$, the following BET equation can be applied to the soil-water system.

$$
\begin{aligned}
\theta=\frac{c x}{(1-x)(1-x+c x)} & \\
c & =\exp \left(\frac{\varepsilon_{S}-\varepsilon_{L}}{R T}\right) \\
x & =\exp \left(-\frac{-\varepsilon_{L}-\mu}{R T}\right)=\frac{a}{a_{O}}
\end{aligned}
$$

where $\theta$ is the adsorbed fraction, $R$ is the gas constant $(\mathrm{J} / \mathrm{Kmol}), T$ is the absolute temperature $(\mathrm{K}), \mu$ is the chemical potential of the solute in the solution $(\mathrm{J} / \mathrm{mol}), a$ is the solute activity $(\mathrm{mol} / \mathrm{kg}$ or mol$/ \mathrm{L})$, and $a_{O}$ is the saturation activity of the solute $(\mathrm{mol} / \mathrm{kg}$ or $\mathrm{mol} / \mathrm{L})$ [23-24]. The $a_{O}$ is given by the $\mathrm{Na}_{2} \mathrm{SO}_{4}$ saturation concentration, $1.54 \mathrm{~mol} / \mathrm{kg}$ (at $25^{\circ} \mathrm{C}$; =1.88 mol/L), multiplied by the activity coefficient.

\subsection{The Langmuir isotherm}

The Langmuir isotherm was applied to the monolayer adsorption of sulfate on the soil. The Langmuir isotherm is as follows:

$$
\begin{aligned}
\theta=\frac{K b}{1+K b} & \\
& R T \ln K=\varepsilon_{S}
\end{aligned}
$$

where $\theta$ is the adsorbed fraction, $b$ is the sulfate activity ( $\mathrm{mol} / \mathrm{mol})$, and $\varepsilon_{\mathrm{S}}$ is the sulfate adsorption energy $(\mathrm{J} / \mathrm{mol})$. When there are two kinds of adsorption sites, a stronger adsorption site and a weaker adsorption site, we can derive the following adsorption equation [24].

$$
Q=q_{1} \frac{K_{1} b}{1+K_{1} b}+q_{2} \frac{K_{2} b}{1+K_{2} b}
$$




$$
R T \ln K_{1}=\varepsilon_{S 1}>R T \ln K_{2}=\varepsilon_{S 2}
$$

where $Q$ is the sulfate adsorption (mol/ $\mathrm{kg}$ ), $q_{1}$ and $q_{2}$ are the maximum sulfate adsorptions at the stronger and weaker adsorption sites $(\mathrm{mol} / \mathrm{kg})$, respectively, and $\varepsilon_{\mathrm{S} 1}$ and $\varepsilon_{\mathrm{S} 2}$ are the sulfate adsorption energies for the stronger and weaker sites ( $\mathrm{J} / \mathrm{mol})$, respectively. Using Eq. (6), two kinds of adsorption sites can be evaluated with the Langmuir equation, while only one kind of site is assumed for the first monolayer when using the BET equation.

\subsection{Activity coefficients}

Activity coefficients were used for calculation of the BET equation and the Langmuir equation. The activity coefficients for concentrations equal to and larger than $50 \mathrm{mmol} / \mathrm{L} \mathrm{Na} \mathrm{SO}_{4}$ were derived using the Pitzer ion-interaction model [25]. Activity coefficients for concentrations smaller than $50 \mathrm{mmol} / \mathrm{L}$ sulfate were calculated using the Davies equation [26].

\section{Results and discussions}

\subsection{Reaction equation for sulfate adsorption}

The soil solution $\mathrm{pH}$ increased when sulfate was adsorbed in the adsorption experiment, except for the solution at $\mathrm{pH} 7$ at concentrations larger than $0.045 \mathrm{mmol} / \mathrm{L}$. In these cases, excess protons were added as a $\mathrm{H}_{2} \mathrm{SO}_{4}$ solution in order to return the $\mathrm{pH}$ to the prescribed value. The added proton-adsorbed sulfate relationship is shown in Fig. 1. The ratio of added proton to sulfate adsorption (the proton/sulfate stoichiometric ratio), $\eta$, represented by the straight line, $y=2 x$, in Fig. 1 was 2.0. The proton/sulfate stoichiometric ratio shows the ratio of proton to sulfate that reacted in the soil-solution system during the sulfate adsorption. The exact amount of reacted proton was the difference between the added proton and the increment in the solution. However, the amount of added proton was assumed to be the same as the amount of reacted proton because the increment in the solution was negligible. At lower sulfate adsorption, the measured values were in the range of the $y=2 x$ line in Fig. 1 . When the adsorption increased, $\eta$ became smaller than 2.0 and the measured values were located above the straight line in Fig. 
1. After the $\eta$ decrease, the number of added proton did not increase and remained almost the same at each $\mathrm{pH}$. The sulfate adsorption at the start of the $\eta$ decrease decreased as the $\mathrm{pH}$ increased. Especially, for $\mathrm{pH} 7$, no measured value was on the straight line, $\mathrm{y}=2 \mathrm{x}$, and only a few values were plotted because amount of added proton was 0 for the other cases. This difference among the $\mathrm{pH}$ values probably indicates a difference in the adsorption reaction.

The obtained proton/sulfate stoichiometric ratio, $\eta=2.0$, differed from ratios reported for other research. These $\eta$ values have ranged from 0.77 to 1.7 for goethite, gibbsite, and allophanic soil in 1 $\mathrm{mmol} / \mathrm{L}$ to $100 \mathrm{mmol} / \mathrm{L}$ background electrolyte solutions [27-28]. This difference is probably caused by the concentrations of background electrolytes. Our background electrolyte concentrations were kept very low in order to avoid the complicated reaction occurring from exchange with other anions.

From this proton/sulfate stoichiometric ratio, $\eta=2.0$, we can work out the details of sulfate adsorption reaction equation. Two adsorption mechanisms on the soil surface can be considered: inner-sphere surface complexation and outer-sphere surface complexation. We first consider formation of the innersphere surface complex. Both bidentate and monodentate formations can be assumed for allophanic soil [15]. From the proton-sulfate adsorption ratio, 2.0, the following reaction equations can be proposed.

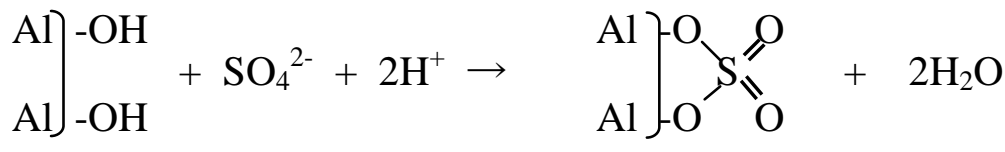

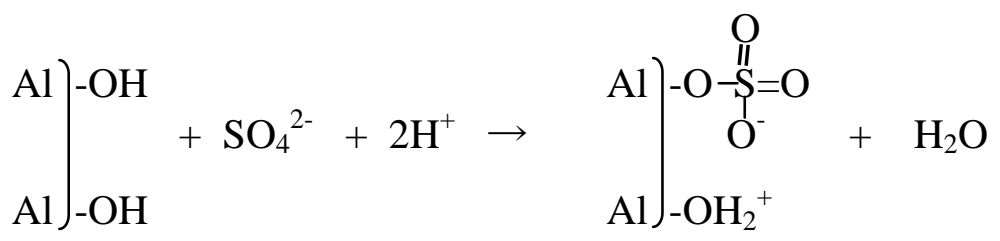

In the case of the outer-sphere surface complex, we can assume

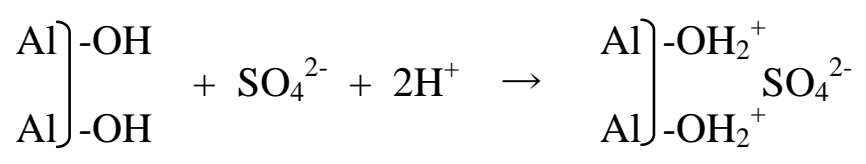

When the total $\mathrm{Na}$ and $\mathrm{SO}_{4}$ concentrations are higher, the concentrations of $\mathrm{NaSO}_{4}{ }^{-}$also increase. In the case of $\mathrm{NaSO}_{4}{ }^{-}$adsorption, several reactions can be assumed. However, if $\mathrm{NaSO}_{4}{ }^{-}$forms an outer- 
sphere surface complex, only one $\mathrm{H}^{+}$reacts. Therefore, when such reaction occurs distinctly, the proton/sulfate stoichiometric ratio does not become $\eta=2.0$. When the total $\mathrm{Na}$ and $\mathrm{SO}_{4}$ concentrations become much higher and multilayer adsorption occurs, it is thought that the surface precipitation of $\mathrm{Na}_{2} \mathrm{SO}_{4}$ predominates. Therefore, for simplicity, the adsorption reaction of $\mathrm{NaSO}_{4}{ }^{-}$is omitted here.

When an adsorption reaction such as (8), (9), or (10) occurs, the solution $\mathrm{pH}$ is kept constant by adding twice the stoichiometric ratio of proton to sulfate adsorption. However, in the experiment, the amount of added proton became almost constant after the sulfate adsorption reached a certain value, even when sulfate adsorption continued to increase. There are two possible explanations for this phenomenon. One is that another compensation reaction occurs at the same time. If the following sodium adsorption reaction occurs simultaneously, the $\mathrm{pH}$ does not change during the sulfate adsorption reaction.

$$
\left.2 \mathrm{Si}]-\mathrm{OH}+2 \mathrm{Na}^{+} \rightarrow 2 \mathrm{Si}\right]-\mathrm{O}^{-} 2 \mathrm{Na}^{+}+2 \mathrm{H}^{+}
$$

Another explanation for the constant amount of added proton is the surface precipitation reaction of $\mathrm{Na}_{2} \mathrm{SO}_{4}$. In this reaction, sulfate can adsorb on the soil surface with no $\mathrm{pH}$ change.

\subsection{Multilayer adsorption}

The measured sulfate adsorption isotherms are shown in Fig. 2. The maximum adsorption could not be detected. The adsorption amount increased as the $\mathrm{pH}$ decreased at lower sulfate concentrations. However, the adsorption amount became almost same among the different $\mathrm{pH}$ conditions when the sulfate concentration was greater than approximately $30 \mathrm{mmol} / \mathrm{L}$. Because the isotherm indicated multilayer adsorption, the BET isotherm was adopted as shown in Fig. 3. In this calculation, the only parameter was the binding energy difference between the monolayer and the other layers, $\Delta \varepsilon=\varepsilon_{\mathrm{S}}-\varepsilon_{\mathrm{L}}$, as expressed in Eq.(2). At lower concentration ranges, the calculated isotherm became larger with increases in the binding energy difference. In other words, the calculated isotherm became larger with increases the binding energy between sulfate and the soil surface. However, the calculated isotherms became similar with increasing concentrations because multilayer adsorption occurred. The measured sulfate 
adsorption isotherms in Fig. 2 were similar in shape to the calculated BET isotherms in Fig. 3. This similarity suggests that the sulfate adsorption energy along with the soil surface increased with decreasing $\mathrm{pH}$ at a lower concentration range.

However, the measured adsorption isotherm could not be fitted with the BET isotherm. Three types of adsorption could be considered on the soil surface: inner-sphere surface complexation (Eq.(8) or Eq.(9)), outer-sphere surface complexation (Eq.(10)), and van der Waals attraction. Here, adsorption in the diffuse layer was negligible because sulfate was strongly adsorbed on the soil surface [10-11]. The soil consisted of different materials, although the predominant surfaces consisted of allophane and imogolite. Therefore, the surface had different adsorption sites, and the proportion of the surface sites that could form surface complexes did not approach unity. This difference in adsorption sites likely caused the difference between the measured isotherm and the BET isotherm.

When the inverse fluorite structure was assumed for the $\mathrm{Na}_{2} \mathrm{SO}_{4}$ precipitation and the sulfate density at the first layer on the soil surface was assumed to be the same as that structure, the calculated sulfate adsorption became approximately $1.0 \mathrm{~mol} / \mathrm{kg}$ (Appendix A). When the $1.0 \mathrm{~mol} / \mathrm{kg}$ scale of the adsorption axis for the measured isotherms was fit to the 1-layer scale of the adsorption axis for the BET isotherms, we got Figure 4. The measured values agreed rather better with the BET equation, though the fit was not good for the initial layers. It was clear that the $\mathrm{Na}_{2} \mathrm{SO}_{4}$ precipitation started at a lower concentration than the saturated concentration, $1.88 \mathrm{~mol} / \mathrm{L}$.

\subsection{Application of the Langmuir isotherm and the surface complexes}

To evaluate the sulfate adsorption mechanisms, the Langmuir equation was applied to the measured isotherms as shown in Fig. 5. The measured isotherms were fitted with Eq.(6) because they could not be fitted with the simple Langmuir Eq.(4). The calculated values agreed well, except at concentrations higher than approximately $25 \mathrm{mmol} / \mathrm{L}$. The disagreement at the higher concentrations was probably caused by the surface precipitation reaction occurring in those regions. The thick lines in Fig. 5 represent the calculated adsorption at the stronger adsorption site. The adsorption energies for each pH condition, 
$R T \ln K_{1}=15.8 R T$, were all the same. The thin lines in Fig. 5 represent the sum of the adsorption at both the stronger and weaker adsorption sites. In these calculations, the total maximum adsorption, $q_{1}+q_{2}$, was assumed to be $0.3 \mathrm{~mol} / \mathrm{kg}$ for all $\mathrm{pH}$ conditions to achieve better agreement with the measured values. The adsorption energies for the weaker sites, $R T \ln K_{2}$, were $9.6 R T$ for $\mathrm{pH} 4,9.0 R T$ for $\mathrm{pH} 5$, 8.7RT for $\mathrm{pH} 6$, and 8.5RT for $\mathrm{pH}$ 7. The energy differences between the stronger and weaker adsorptions were from $6.2 R T$ to $7.3 R T$.

The sulfate adsorption at the stronger energy sites increased with decreasing $\mathrm{pH}$ and that at the weaker energy sites increased with increasing $\mathrm{pH}$. These results agree well with other experimental research for allophanic soil; adsorbed sulfate has been reported to be easily desorbed with water at neutral $\mathrm{pH}$, but at lower $\mathrm{pH}$ it remains even with washing with $1 \mathrm{~mol} / \mathrm{L} \mathrm{KCl}$ [13]. Recent spectroscopic results are also in agreement with our results; sulfate has been found to form both outer-sphere and inner-sphere surface complexes on goethite, with the latter increasing with decreasing pH [18-20]. It was therefore supposed that the thick lines correspond to the inner-sphere complex and that the following thin lines correspond to the outer-sphere complex. The calculated adsorption energies for the stronger adsorption site, $15.8 R T$, and for the weaker adsorption site, around $9 R T$, were also reasonable values for the inner-sphere and outer-sphere complexes, respectively.

\subsection{Consideration with the law of mass action}

The following equation is derived from the adsorption reaction equation (8) adopting the law of mass action.

$$
K_{\text {in }}=\frac{\left[-\mathrm{Al}_{2} \mathrm{SO}_{4}\right]}{\left.\left[-(\mathrm{AlOH})_{2}\right]\left[\mathrm{SO}_{4}{ }^{2-}\right] \mathrm{H}^{+}\right]^{2}}
$$

where [ ] indicates the activity. Assuming that the site for the inner-sphere complex is independent, Eq.(12) is changed as follows:

$$
\frac{\theta_{C}}{1-\theta_{C}}=K_{i n}\left[H^{+}\right]^{2}\left[\mathrm{SO}_{4}{ }^{2-}\right]
$$


where $\theta_{\mathrm{C}}$ is the adsorbed fraction at the corresponding site, and $K_{\mathrm{in}}$ is the intrinsic constant. This equation (13) is similar to the Langmuir equation (4). Then,

$$
K=K_{\text {in }}\left[H^{+}\right]^{\mathbf{T}}
$$

where $K$ is the constant of the Langmuir equation (4). The same equation (14) is derived for both cases of the adsorption reaction equation (9) and (10), assuming that the site is completely occupied with sulfate on the right side of the reaction equation.

We neglected the effects of the electric potential near the soil surface because sulfate adsorption in the diffuse layer and the $\zeta$ potential are negligible when sulfate is the only major anion in the soil [11]. Even supposing the existence of the Stern potential, $\Psi_{\mathrm{S}}$, the effect of electric potential disappeared as described below. In the case of adsorption reactions (8) to (10) in the presence of the Stern potential, $\Psi_{\mathrm{S}}$,

$$
\frac{\theta_{C}}{1-\theta_{C}}=K_{i n}\left[H^{+}\right]\left[S O_{4}^{2-}\right]=K_{i n}\left(H^{+}\right)^{2}\left\{\exp \frac{-\Psi_{S} F}{R T}\right\}^{2}\left(S O_{4}^{2-}\right) \exp \frac{2 \Psi_{S} F}{R T}=K_{i n}\left(H^{+}\right)^{2}\left(S O_{4}^{2-}\right)
$$

where [ ] $]_{S}$ is the activity in the Stern layer, ( ) is the bulk activity, and $F$ is the Faraday constant.

When $K=7.0 \times 10^{6}(R T \ln K=15.8 R T)$ was adopted in the Langmuir equation, the calculated isotherm agreed with the measured values at $\mathrm{pH} 4$, as shown in Fig. 5 . Based on $K=7.0 \times 10^{6}$ at $\mathrm{pH} 4$, the $K$ became $7.0 \times 10^{4}$ at $\mathrm{pH} 5,700$ at $\mathrm{pH}$ 6, and 7.0 at $\mathrm{pH} 7$ using both Eqs. (14) and (15). The $K$ value became smaller as the $\mathrm{pH}$ increased according to the law of mass action. However, the calculated isotherms using such $K$ values at $\mathrm{pH} \mathrm{5,} \mathrm{6,} \mathrm{and} 7$ became much smaller than the measured values. Based on the measured isotherms, the $K$ value for the stronger adsorption site was constant among different $\mathrm{pH}$ values, although the maximum adsorption, $q_{1}$, decreased with increasing $\mathrm{pH}$. Therefore, the isotherm could not be evaluated from the law of mass action as written above.

It is not easy to predict complexation constants, and these sometimes have to be treated as adjustable parameters [29-30]. Rietra et al. [21] have predicted these constants by using the Charge Distribution Multisite Complexation Model in constant electrolyte concentration backgrounds, which is based on the adsorption reaction equation and the charge distribution of adsorbed ions. They succeeded in adjusting 
the predicted values with the measured values. However, their model could not directly predict the relative amounts of inner-sphere and outer-sphere surface complexes. More detailed research is therefore required to accurately predict sulfate surface complexation.

\section{Summary}

Three types of sulfate adsorption for the allophanic Andisol were indicated by the measured and theoretical adsorption isotherms. Surface precipitation was detected by the measured adsorption isotherms, which showed multilayer adsorption. The BET isotherm confirmed this multilayer adsorption. The presence of stronger and weaker adsorption sites was suggested by using the Langmuir isotherm for the monolayer adsorption. The adsorption energies obtained from the Langmuir equation and recent spectroscopic analysis suggested that the stronger adsorption corresponded to inner-sphere surface complex and the weaker adsorption to outer-sphere surface complexation.

\section{References}

[1] R. G. Ford, A. C. Scheinost, D. L. Sparks, Adv. Agron. 74 (2001) 41.

[2] K. J. Farley, D. A. Dzombak, F. M. M. Morel, J. Colloid Interface Sci. 106 (1985) 226.

[3] R. A.Griffin, J. J. Jurinak, Soil Sci. Soc. Am. Proc. 37 (1973) 847.

[4] R. W. Taylor, B. G. Ellis, Soil Sci. Soc. Am. J. 42 (1978) 432.

[5] A. A. Mehadi, R. W. Taylor, Soil Sci. Soc. Am. J. 52 (1988) 627.

[6] T. T. Chao, M. E. Harward, S. C. Fang, Soil Sci. Soc. Am. Proc. 26 (1962) 234.

[7] K. Wada, Y. Okamura, J. Soil Sci. 31 (1980) 307.

[8] M. Ishiguro, K-C. Song, K. Yuita, Soil Sci. Soc. Am. J. 56 (1992) 1789. 
[9] T. Nakagawa, M. Ishiguro, J. Environ. Qual. 23 (1994) 208.

[10] M. Ishiguro, T. Nakajima, Soil Sci. Soc. Am. J. 64 (2000) 813.

[11] M. Ishiguro, K. Nakaishi, T. Nakajima, Colloids Surf. A Physicochem. Eng. Aspects 230 (2003) 81.

[12] M. Ishiguro, Y. Manabe, S. Seo, T. Akae, Soil Sci. Plant Nutr. 49 (2003) 249.

[13] H. Gebhardt, N. T. Coleman, Soil Sci. Soc. Am. Proc. 38 (1974) 259.

[14] S. S. S. Rajan, Soil Sci. Soc. Am. J. 43 (1979) 65.

[15] G. N. Padilla, N. Matsue, T. Henmi, Clay Sci. 12 (2002) 33.

[16] K. B. Marsh, R. W. Tillman, J. K. Syers, Soil Sci. Soc. Am. J. 51 (1987) 318.

[17] N. U. Yamaguchi, M. Okazaki, T. Hashitani, J. Colloid Interface Sci. 209 (1999) 386.

[18] D. Peak, R. G. Ford, D. L. Sparks, J. Colloid Interface Sci. 218 (1999) 289.

[19] J. D. Ostergren, G. E. Brown, Jr., G. A. Parks, P. Persson, J. Colloid Interface Sci. 225 (2000) 483.

[20] H. Wijnja, C. P. Schulthess, J. Colloid Interface Sci. 229 (2000) 286.

[21] R. P. J. J. Rietra, T. Hiemstra, W. H. van Riemsdijk, J. Colloid Interface Sci. 240 (2001) 384.

[22] National Institute of Agricultural Sciences. Materials of Department of Chemistry 3, Natl. Inst. Agric. Sci., 1984, p.1. (in Japanese)

[23] S. Brunauer, P. H. Emmett, E. Teller, J. Am. Chem. Soc. 60 (1938) 309.

[24] S. Ooi, in; Y. Adachi, S. Iwata (eds.), Soil Colloidal Phenomena, Japan Scientific Societies Press, Tokyo, 2003, p323. (in Japanese)

[25] J. K. Hovey, K. S. Pitzer, J. A. Rard, J. Chem. Thermodynamics 25 (1993) 173.

[26] M. E. Essington, Soil and Water Chemistry, CRC Press, Boca Raton, 2004, p190. 
[27] E. Kartun, Eur. J. Soil Sci. 48 (1997) 483.

[28] R. P. J. J. Rietra, T. Hiemstra, W. M. van Riemsdijk, Geochim. Cosmochim. Acta 63 (1999) 3009.

[29] L. K. Koopal, in; J. S. Laskowski, J. Ralston (eds.), Colloid Chemistry in Mineral Processing, Elsevier, Amsterdam, 1992, p.37.

[30] L. K. Koopal, Electrochimica Acta 41 (1996) 2293. 


\section{Figure legends}

Fig. 1. Sulfate adsorption and added protons to maintain constant $\mathrm{pH}$ in the adsorption experiment. A $\mathrm{H}_{2} \mathrm{SO}_{4}$ solution was added for the $\mathrm{pH}$ adjustment.

Fig. 2. Measured sulfate adsorption isotherms.

Fig. 3. The calculated BET isotherms. Values for the lines denote the binding energy difference between the monolayer and the other layers, $\Delta \varepsilon=\varepsilon_{S}-\varepsilon_{\mathrm{L}}$, as expressed in Eq.(2). The unit in the ordinate, Layer, indicates the covering ratio of sulfate on the soil surface.

Fig. 4. The measured sulfate adsorption isotherms and the calculated BET isotherms. The calculated BET isotherms are shown with the lines. The inverse fluorite structure was assumed to the $\mathrm{Na}_{2} \mathrm{SO}_{4}$ precipitation for the calculation. Values for the lines denote the binding energy difference between the monolayer and the other layers. The unit in the ordinate, Layer=mol/kg, denotes both the covering ratio of sulfate on the soil surface and the moles of sulfate per kg of dry soil, because 1 Layer covering equals $1 \mathrm{~mol} / \mathrm{kg}$ when the inverse fluorite structure is assumed.

Fig. 5. The measured sulfate adsorption isotherms and the calculated Langmuir isotherms. The thick lines were obtained using Eq.(4). The thin lines were obtained using Eq.(6). 


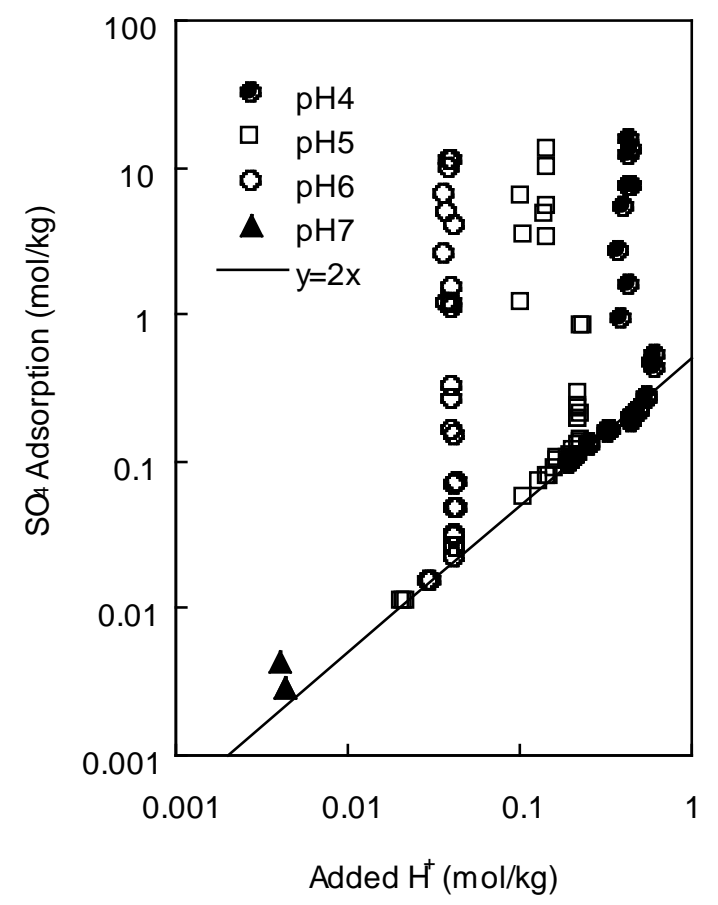

Fig. 1. Sulfate adsorption and added protons to maintain constant $\mathrm{pH}$ in the adsorption experiment. A $\mathrm{H}_{2} \mathrm{SO}_{4}$ solution was added for the $\mathrm{pH}$ adjustment. 


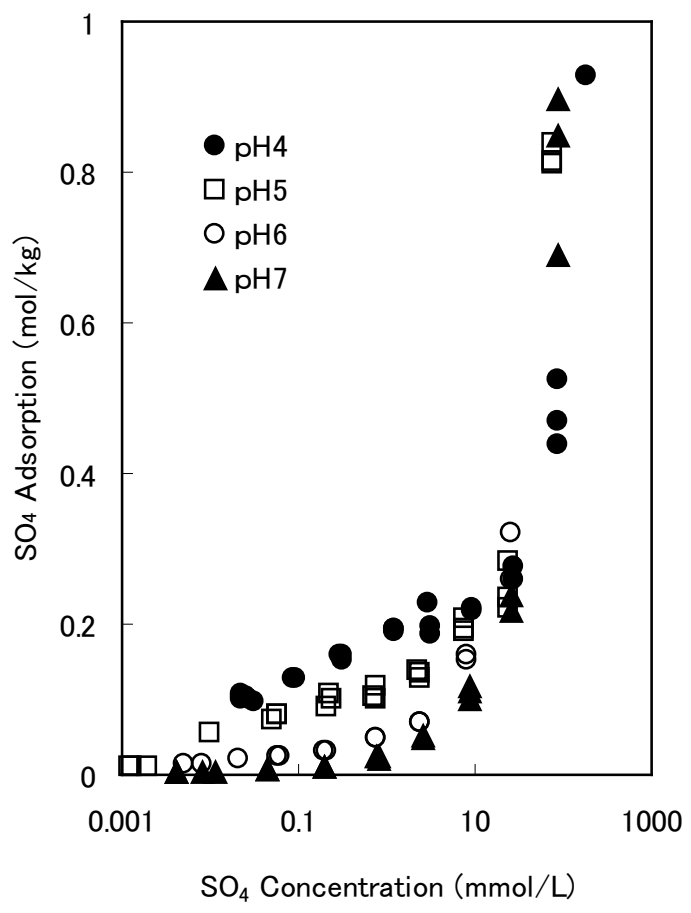

Fig. 2. Measured sulfate adsorption isotherms. 


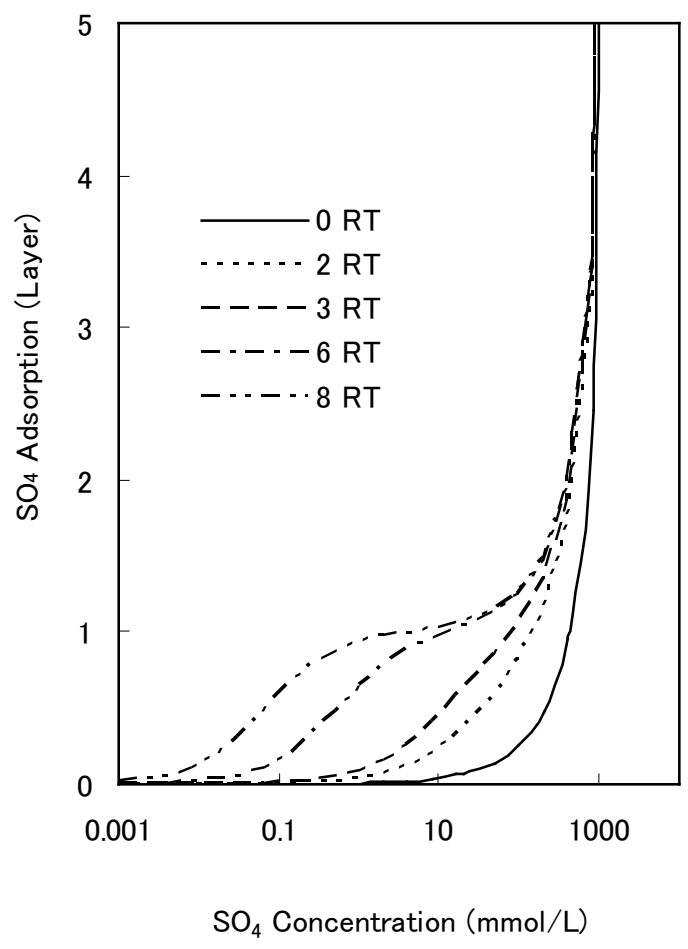

Fig. 3. The calculated BET isotherms. Values for the lines denote the binding energy difference between the monolayer and the other layers, $\Delta \varepsilon=\varepsilon_{S}-\varepsilon_{\mathrm{L}}$, as expressed in Eq.(2). The unit in the ordinate, Layer, indicates the covering ratio of sulfate on the soil surface. 


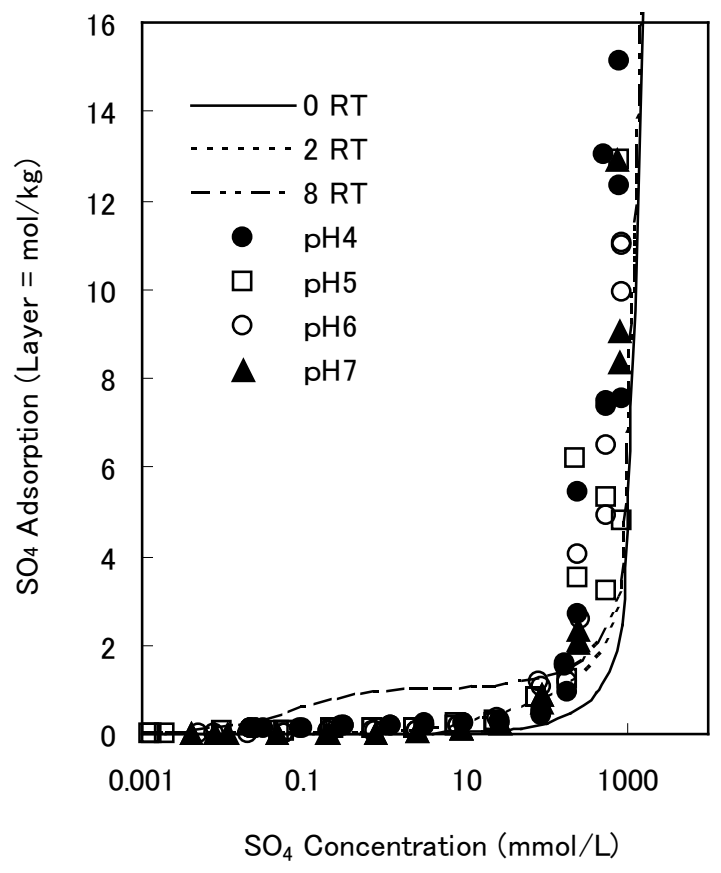

Fig. 4. The measured sulfate adsorption isotherms and the calculated BET isotherms. The calculated BET isotherms are shown with the lines. The inverse fluorite structure was assumed to the $\mathrm{Na}_{2} \mathrm{SO}_{4}$ precipitation for the calculation. Values for the lines denote the binding energy difference between the monolayer and the other layers. The unit in the ordinate, Layer=mol/kg, denotes both the covering ratio of sulfate on the soil surface and the moles of sulfate per kg of dry soil, because 1 Layer covering equals $1 \mathrm{~mol} / \mathrm{kg}$ when the inverse fluorite structure is assumed. 


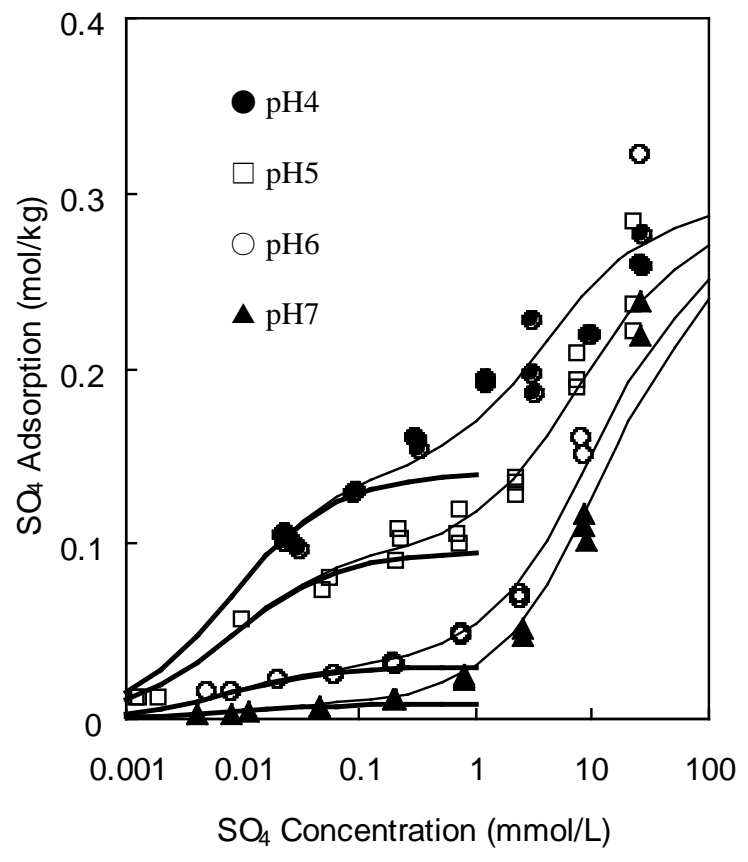

Fig. 5. The measured sulfate adsorption isotherms and the calculated Langmuir isotherms. The thick lines were obtained using Eq.(4). The thin lines were obtained using Eq.(6). 
Table 1. Physical and chemical characteristics of the soil. (National Institute of Agricultural

Sciences, 1984) [22]

\begin{tabular}{lc}
\hline Soil characteristics & \\
\hline Coarse sand & $1.7 \%$ \\
Fine sand & $11.2 \%$ \\
Silt & $37.5 \%$ \\
Clay & $49.5 \%$ \\
$\quad$ Amorphous material & $41.4 \%$ \\
(with allophone + imogolite) & \\
\multicolumn{1}{c}{ Free oxide $\mathrm{Al}_{2} \mathrm{O}_{3}$} & $2.4 \%$ \\
$\quad \mathrm{Fe}_{2} \mathrm{O}_{3}$ & $4.7 \%$ \\
Kaolinite & $3.4 \%$ \\
$\quad$ Al-vermiculite, Chrorite & trace \\
Organic C & $1.16 \%$ \\
Texture class & $\mathrm{Heavy} \mathrm{clay}$ \\
Porosity & $82.4 \%$ \\
Bulk density & $510 \mathrm{~kg} / \mathrm{m}^{3}$ \\
Cation exchange capacity & \\
pH 5 & $5.7 \mathrm{cmol}_{\mathrm{c}} / \mathrm{kg}$ \\
pH 7 & $10.6 \mathrm{cmol}_{\mathrm{c}} / \mathrm{kg}$ \\
Anion exchange capacity & \\
pH 5 & $10.3 \mathrm{cmol}_{\mathrm{c}} / \mathrm{kg}$ \\
pH 7 & $0.6 \mathrm{cmol} / \mathrm{kg}$ \\
\hline
\end{tabular}

